\title{
Genetic analysis of faecal worm egg count in South African Merinos under natural challenge
}

\author{
S.W.P. Cloete ${ }^{1,2 \#}$, J.J. Olivier ${ }^{3}$, E. du Toit ${ }^{4}$ and F.H. Dreyer ${ }^{5}$ \\ ${ }^{1}$ Department of Animal Sciences, Stellenbosch University, Private Bag X1, Matieland 7602, South Africa \\ ${ }^{2}$ Institute for Animal Production: Elsenburg, Private Bag X1, Elsenburg 7607, South Africa \\ ${ }^{3}$ ARC: Livestock Business Division, Private Bag X5013, Stellenbosch 7599, South Africa \\ ${ }^{4}$ Tygerhoek Research Farm, P.O. Box 25, Riviersonderend 7520, South Africa \\ ${ }^{5}$ Western Cape Provincial Veterinary Laboratory, Private Bag X5020, Stellenbosch 7599, South Africa
}

\begin{abstract}
Sheep from a Merino selection experiment at the Tygerhoek research farm in the Southern Cape provided material for this study. The selection lines involved included a line selected for clean fleece weight, a "Wet and Dry" line, a fine wool line and an unselected Control line. Rectal faeces samples were obtained from individual animals at 13 to 16 months of age, after drenching was withheld for at least 10 weeks. Nematode eggs in these samples were counted. Fitting the appropriate fixed effects, the heritability of untransformed, cube root transformed and log transformed faecal nematode egg count (FEC) was obtained from single-trait analyses. The effects of sex and birth year were involved in a significant interaction. Means for FEC were generally higher in ram progeny than in ewes, but the magnitude of the sex difference was not consistent. Multiple lambs had a slightly lower mean for FEC than singles, while FEC was unaffected by dam age. The heritability of FEC was estimated at between 0.14 for untransformed data and 0.18 for log transformed FEC. Genetic correlations of log transformed FEC with two-tooth staple strength $(-0.49)$ and coefficient of variation of fibre diameter (0.30) were favourable. Clean fleece weight was unfavourably related to FEC on a genetic level (0.19). Selection for resistance to parasitic nematodes after natural challenge should thus be feasible in the Merino lines studied.
\end{abstract}

Keywords: Fleece weight, genetic correlation, heritability, live weight, resistance

\#Corresponding author. E-mail: schalkc@elsenburg.com

\section{Introduction}

The usage of chemicals to control external and internal parasites of livestock is being challenged on a global scale. Resistance of gastro-intestinal nematodes to the present generation drugs is commonly experienced (Bath, 2006), while indications are that no new drenches are in the process of being developed. Existing strategies for the control of these pathogens are thus challenged (Bath, 2006), and alternative strategies need to be formulated (Vatta et al., 2000).

A possible avenue for dealing with the challenge of gastro-intestinal helminths is to select livestock for resistance and/or tolerance to infestation (Vatta et al., 2000). Research in other countries demonstrated genetic variation in resistance of sheep to nematode infestations (Greeff et al., 1995; Morris et al., 1996; Greeff \& Karlsson, 1999; Khusro et al., 2004), and successful breeding programs for resistance/tolerance have been reported (Woolaston \& Piper, 1996; Greeff et al., 1999; Morris et al., 2005). Farming with resistant strains of sheep will result in a reduced reliance on anthelmintics to control parasitic nematodes, and associated economic advantages (McEwan et al., 1995). The economic output of a resistant Merino strain was markedly higher than that of a control strain when no drenching was administered (Greeff et al., 2006). The strains assessed were of equal genetic merit for production traits, and they grazed separate pastures where cross-contamination was impossible.

South African research on genetic parameters for resistance to gastro-intestinal nematodes of sheep is limited to a few studies (Cloete et al., 2000; Bisset et al., 2001; Nieuwoudt et al., 2002; Snyman, 2007). No studies on genetic correlations of faecal worm egg counts (FEC) with other traits of economic interest have been published, apart from a preliminary study on the Tygerhoek Merino flock (Cloete et al., 2000). International studies on these correlations are accordingly scarce, with fewer than five estimates for genetic 
correlations of wool traits with FEC listed in the comprehensive review of Safari et al. (2005) on genetic parameters for sheep. The need for further studies on this topic is evident from these comments.

Against this background, the present study reports environmental factors impacting on FEC, estimates of the heritability of FEC before and after transformation as well as genetic correlations of FEC with live weight and wool traits. Based on previously derived selection line differences for FEC (Cloete et al., 2000), breeding values for animals belonging to four single trait selection lines were also compared.

\section{Material and Methods}

Merino sheep from different selection lines on the Tygerhoek research farm in the Southern Cape area of South Africa provided material for the study. The climate at the site is Mediterranean, with a total annual precipitation of $425 \mathrm{~mm}$, of which $\sim 60 \%$ is recorded from April to September. The following selection lines were involved:

- Fleece weight - This line was selected since 1970 for an increase in clean fleece weight with a check on fibre diameter (Cloete et al., 1998).

- Wet and Dry - Ewes in this line have been culled since 1993 on failure to lamb or to rear at least one lamb per lambing opportunity. During this period, rams were selected as was described by Cloete \& Scholtz (1998). This line was discontinued in 2002, and data are only available up to the 2002 drop.

- Fine wool - This line was descended from a similar line maintained at Cradock (Olivier et al., 1999), of which ewes were introduced to Tygerhoek during 1997. During the formation of this line, ewes were screened from their flocks of origin on the basis of a low fibre diameter and an above average live weight.

- Control - no directed selection was applied to this line since 1970, although a measure of random genetic drift was measured in some traits (Cloete et al., 1998). It is maintained as a control for the other lines.

No directed selection for resistance to gastro-intestinal nematodes was applied in any of the lines. Progeny were maintained in single flocks (separated on sex) throughout the trial. Rectal faeces samples were obtained from individual animals at 13 to 16 months of age, after drenching was withheld for at least 10 weeks. Sampling took place during the years from 1995 to 2005. The exception was the progeny group of 2004, of which no samples were taken. Sampling generally took place in the winter-spring months of JulySeptember. The heritability of FEC after natural infection was shown to be highest during the period from June to September under Mediterranean conditions in Western Australia (Greeff et al., 1995). Experience of the pathogen species present at the experimental site during this time of the year suggest that the animals were likely to be subjected to a mixed challenge by Ostertagia and Trychostrongylus spp. The number of nematode eggs per sample was counted at the Western Cape Provincial Veterinary Laboratory, using the McMaster technique, with a sensitivity of 100 eggs per gram of wet faeces (Van Schalkwyk et al., 1994). During the same period FEC was recorded, two-tooth data were also recorded. The traits under consideration included two-tooth live weight, clean fleece weight, fibre diameter, staple strength, coefficient of variation (CV) of fibre diameter and total fold score. These recordings were made on 2127 to 3470 individuals, born during the period from 1995 to 2005.

Untransformed FEC data were skew and leptokurtic (Table 1). These data were thus subjected to a cube root or log transformation. Both these transformations are commonly used to normalise FEC data (Eady, 1995; Woolaston \& Piper, 1996; Khusro et al., 2004; Morris et al., 2005). The natural logarithm of FEC was computed, after 100 were added to FEC to account for zero counts. Both transformations markedly improved the distribution of the data, as depicted in Table 1. The ASREML program (Gilmour et al., 1999) was used for the analysis of the fixed effects, and also subsequently to estimate variance components in single-trait animal model analyses. The first analysis involved fitting various combinations of fixed effects to obtain an operational model, including the effects of birth year (1995-2003; 2005), sex (male and female), age of dam ( $2-7$ years) and birth type (singles and pooled multiples). All two-factor interactions were considered initially, but only the birth year $\mathrm{x}$ sex interaction was significant and was retained. Effects found to be significant $(\mathrm{P}<0.05)$ in these preliminary analyses were included in an operational model for subsequent analyses. Random terms were added to the operational model, resulting in the following models for analyses (in matrix notation): 


$$
\begin{aligned}
& \mathrm{y}=\mathrm{Xb}+\mathrm{Z}_{1} \mathrm{a}+\mathrm{e} \\
& \mathrm{y}=\mathrm{Xb}+\mathrm{Z}_{1} \mathrm{a}+\mathrm{Z}_{2} \mathrm{C}+\mathrm{e} \\
& \mathrm{y}=\mathrm{Xb}+\mathrm{Z}_{1} \mathrm{a}+\mathrm{Z}_{3} \mathrm{~m}+\mathrm{e} \\
& {[\text { Covariance }(\mathrm{a}, \mathrm{m})=0]} \\
& \mathrm{y}=\mathrm{Xb}+\mathrm{Z}_{1} \mathrm{a}+\mathrm{Z}_{3} \mathrm{~m}+\mathrm{Z}_{2} \mathrm{c}+\mathrm{e} \\
& {[\text { Covariance }(\mathrm{a}, \mathrm{m})=0]} \\
& \mathrm{y}=\mathrm{Xb}+\mathrm{Z}_{3} \mathrm{a}+\mathrm{Z}_{3} \mathrm{~m}+\mathrm{Z}_{2} \mathrm{C}+\mathrm{e} \\
& {\left[\text { Covariance }(\mathrm{a}, \mathrm{m})=\mathrm{A} \sigma_{\mathrm{am}}\right]}
\end{aligned}
$$

In these analyses, $\mathrm{y}$ was a vector of observations for untransformed FEC, cube root transformed FEC or $\log$ transformed FEC, and b, a, $m$ and c vectors of fixed effects, direct genetic variances, maternal genetic variances and maternal permanent environmental variances respectively. $\mathrm{X}, \mathrm{Z}_{1}, \mathrm{Z}_{2}$ and $\mathrm{Z}_{3}$ were the corresponding incidence matrices relating the respective effects to $\mathrm{y}$, while e was the vector of residuals. A was the numerator relationship matrix, and $\sigma_{\mathrm{am}}$ the covariance between direct genetic and maternal genetic effects.

It was assumed that:

$$
\mathrm{V}(\mathrm{a})=\mathrm{A} \sigma_{\mathrm{a}}^{2} ; \mathrm{V}(\mathrm{m})=\mathrm{A} \sigma_{\mathrm{m}}^{2} ; \mathrm{V}(\mathrm{c})=\mathrm{I} \sigma_{\mathrm{c}}^{2} ; \mathrm{V}(\mathrm{e})=\mathrm{I} \sigma_{\mathrm{e}}^{2}
$$

With I being identity matrixes; $\sigma_{\mathrm{a}}^{2}, \sigma_{\mathrm{m}}^{2}, \sigma_{\mathrm{c}}^{2}$ and $\sigma_{\mathrm{e}}^{2}$ the direct genetic variance, maternal genetic variance and the maternal permanent environmental variance and environmental (residual) variance, respectively. These analyses yielded estimates of genetic and permanent environmental variances. Ratios for direct additive genetic and maternal permanent environmental variances were computed from these estimates. These variances were expressed relative to the total phenotypic variance. Likelihood Ratio tests (LRT) were performed to assess the significance of the contribution of each random term to improvements in the model for analysis. The LRT is based on testing twice the increase in Log-likelihood resulting from adding a random term to the model of analysis as a $\mathrm{Chi}^{2}$ statistic. Alternatively, for two models with the same number of random terms, and assuming identical fixed effect modelling, the model with the higher value for the Log-likelihood fits the data better. All analyses included the full pedigree file of animals from 1969 to 2005, consisting of 10850 individuals, the progeny of 949 sires and 3603 dams. Subsequently, twotrait animal models were fitted to calculate all relevant direct and maternal correlations of log transformed FEC with two-tooth live weight and wool traits. The wool traits under consideration were clean fleece weight, fibre diameter, staple strength, CV of fibre diameter and total fold score. Details of the single-trait and two-trait analyses on these two-tooth traits were omitted as it was recently reported by Matebesi et al. (2007), and the present analysis did not add any new information on the (co)variances among them.

Direct breeding values for log transformed FEC were obtained from the single-trait analysis with the best log likelihood, and averaged for the respective selection lines within birth years. Genetic trends derived in this way were inspected for differences between lines, using standard errors of the means to inspect line differences within birth years for significance. These breeding values were obtained from an analysis where selection line and its interactions with other traits were excluded from the operational model.

\section{Results}

Descriptive statistics for untransformed FEC indicated extreme variation and a non-normal distribution (Table 1). The properties of the data were markedly improved by the transformations applied, which validate the usage of these transformations. The log transformation improved the extreme variance in particular, resulting in a coefficient of variation of below $20 \%$.

The type of transformation that was applied resulted in minimal changes in conclusions derived from the data as pertaining to the fixed effects analysed. Only the results obtained from the analysis involving log transformed FEC will thus be presented. Fixed effects that influenced the data significantly were sex, birth year the sex $x$ birth year interaction (all $\mathrm{P}<0.01)$ as well as birth type $(\mathrm{P}<0.05)$. The effect of selection line approached significance $(\mathrm{P}=0.06)$, while FEC was independent of dam age. In general, ewes excreted fewer worm eggs in their faeces than rams (Figure 1). However, the magnitude of the difference between 
Table 1 Descriptive statistics for the faecal worm egg counts (FEC in eggs per gram wet faeces) of 3560 Merino two-tooth sheep from the Tygerhoek Merino flock during the period from 1995 to 2005

\begin{tabular}{|c|c|c|c|c|c|}
\hline Trait & $\begin{array}{l}\text { Mean } \\
\pm \text { s.d. }\end{array}$ & Range & $\begin{array}{l}\mathrm{CV} \\
(\%)\end{array}$ & Skewness & Kurtosis \\
\hline FEC & $\begin{array}{c}799 \\
\pm 1204\end{array}$ & $0-13700$ & 151 & 3.451 & 19.051 \\
\hline Cube root of FEC & $\begin{array}{c}6.93 \\
\pm 4.67\end{array}$ & $0-23.85$ & 67 & 0.081 & -0.464 \\
\hline Log of $(\mathrm{FEC}+100)$ & $\begin{array}{r}6.15 \\
\pm 1.15 \\
\end{array}$ & $4.61-9.53$ & 19 & 0.199 & -0.917 \\
\hline
\end{tabular}

rams and ewes differed between years, resulting in the observed interaction. During the earliest (1995 and 1996) and the most recent production years (2003 and 2005) the differences in FEC between ewes and rams were particularly large.

Multiple lambs had slightly lower means for log transformed FEC’s than singles (6.11 \pm 0.04 vs. 6.19 \pm 0.04 , respectively; $\mathrm{P}<0.05$ ). Respective geometric means obtained by back transformation amounted to 354 for multiples compared to 388 for singles. Least squares means for log transformed FEC ranged from $6.09 \pm 0.08$ for the progeny of 7-year-old dams to $6.20 \pm 0.05$ for the progeny of 4-year-old dams $(\mathrm{P}>0.10)$. Since detailed attention is given to the averaged breeding values of animals in the respective selection lines, no results for the phenotypic selection line differences will be presented here.

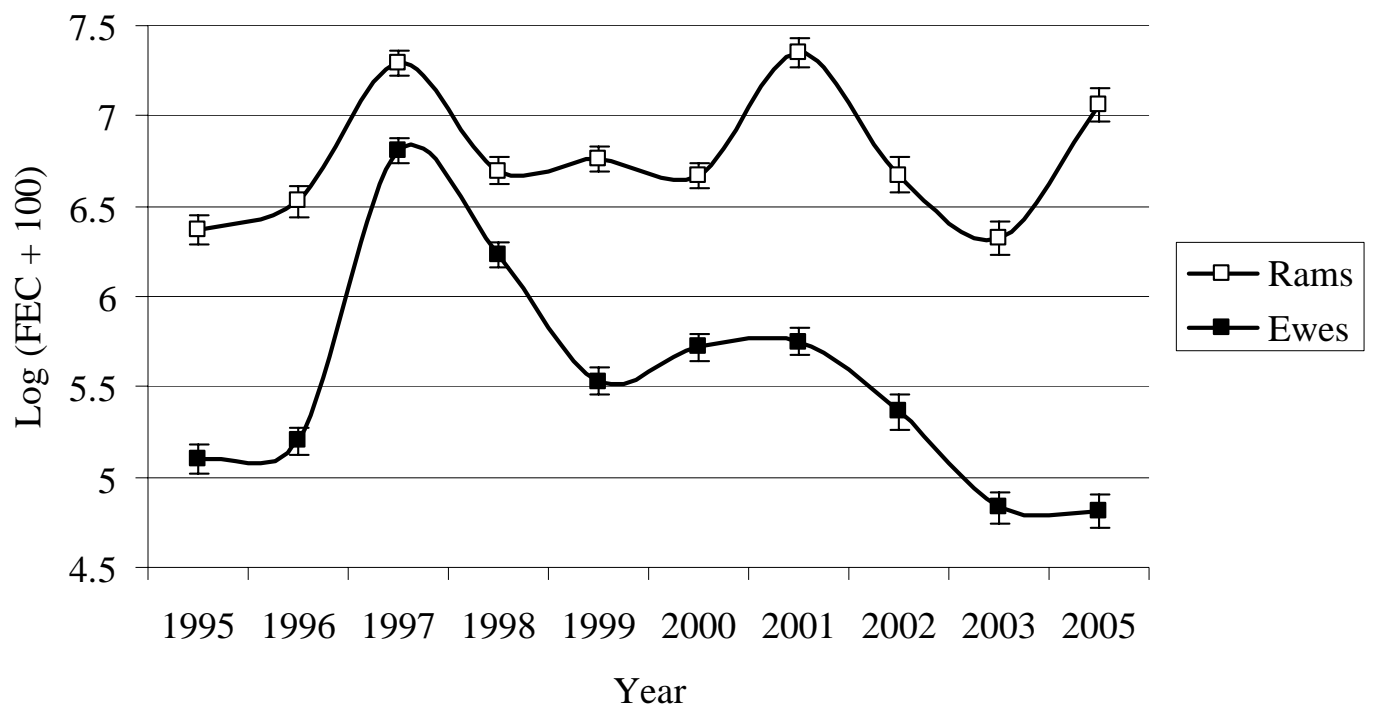

Figure 1 Least squares means depicting the interaction between birth year and sex for FEC in two-tooth animals from the Tygerhoek flock. Vertical bars about the means depict appropriate standard errors. (FEC - faecal worm egg count)

The single-trait animal model fitting the data best included direct additive effects as the only significant random source of variation in the case of untransformed FEC (Table 2). The "best" model for both cube root and log transformed FEC included direct additive and dam permanent environmental effects as random.

Heritability estimates derived from the variance components amounted between 0.14 for untransformed data to 0.18 for log transformed data, the estimate for cube root transformed data being intermediate (Table 3). Although the derived $\mathrm{h}^{2}$ estimates did not differ from each other (when the s.e.'s 
provided were considered), there is some evidence that the transformation of the data to ensure a better distribution resulted in a slightly higher estimate of the direct additive variation. Maternal variance components were of smaller magnitude for the transformed data sets, and accounted for $\sim 5 \%$ of the overall phenotypic variation.

Table 2 Log Likelihood ratios for the respective random effects models fitted to the FEC data of two-tooth animals from the Tygerhoek flock. The model of choice is depicted in bold figures

\begin{tabular}{lccc}
\hline \multicolumn{1}{c}{ Effects } & FEC & Cube root of FEC & Log of (FEC + 100) \\
\hline Fixed effects only & -6454.38 & -6327.83 & -1377.53 \\
Fixed $+\mathrm{h}^{2}$ & $\mathbf{- 6 4 2 7 . 5 8}$ & -6282.64 & -1329.13 \\
Fixed $+\mathrm{h}^{2}+\mathrm{c}^{2}$ & -6427.31 & $\mathbf{- 6 2 7 9 . 0 4}$ & $\mathbf{- 1 3 2 5 . 7 6}$ \\
Fixed $+\mathrm{h}^{2}+\mathrm{m}^{2}$ & -6426.14 & -6280.80 & -1327.58 \\
Fixed $+\mathrm{h}^{2}+\mathrm{m}^{2}+\mathrm{c}^{2}$ & -6426.14 & -6279.02 & -1325.75 \\
Fixed $+\mathrm{h}^{2}+\mathrm{m}^{2}+\mathrm{r}_{\mathrm{am}}+\mathrm{c}^{2}$ & -6426.26 & -6277.33 & -1324.49
\end{tabular}

FEC - faecal worm egg count

Table 3 Variance components and ratios ( \pm s.e.) for FEC data of two-tooth animals from the Tygerhoek Merino flock

\begin{tabular}{lccc}
\hline Component or ratio & FEC & Cube root of FEC & Log of (FEC + 100) \\
\hline Variance components: & & & \\
Direct additive & 163228 & 2.1641 & 0.14208 \\
Maternal PE & - & 0.65573 & 0.03754 \\
Residual & 964399 & 9.93791 & 0.59589 \\
Variance ratios: & & & \\
$\mathrm{h}^{2}$ & $0.144 \pm 0.029$ & $0.170 \pm 0.032$ & $0.183 \pm 0.033$ \\
$\mathrm{c}^{2}$ & - & $0.051 \pm 0.019$ & $0.048 \pm 0.019$ \\
\hline
\end{tabular}

FEC - faecal worm egg count

Pearson's correlations among the predicted breeding values derived from the respective data sets were computed. The correlation of untransformed FEC data with cube root transformed data amounted to 0.869. The corresponding correlation was 0.870 for the analysis involving log transformed FEC data. Breeding values derived from cube root transformed FEC data were highly correlated to log transformed FEC, the applicable correlation being 0.991 .

It was hypothesised that the lower means for FEC in female animals may have resulted in these animals not being able to express their genetic superiority in terms of resistance to gastro-intestinal nematodes because of an inadequate natural challenge. Separate analyses were therefore conducted within gender groups to test this hypothesis. The overall mean for FEC in 1899 females was markedly lower than that of 1661 males. Respective mean values ( \pm s.d.) were $385 \pm 748$ vs. $1273 \pm 1431$ for untransformed data, $4.83 \pm 4.10$ vs. $9.32 \pm 4.10$ for cube root transformed data and $5.62 \pm 0.98$ vs. $6.75 \pm 1.08$ for log transformed data. Despite these marked gender differences in FEC, no difference was found in the derived $\mathrm{h}^{2}$ estimates from the respective gender groups. As a matter of fact, the $\mathrm{h}^{2}$ estimate for log transformed FEC obtained 
from females $(0.226 \pm 0.048)$ was slightly larger in absolute terms than the estimate of $0.203 \pm 0.056$ derived for males. Part of the phenotypic variation was partitioned to a dam permanent environmental variance ratio of $0.081 \pm 0.039$ in rams, while no such effect was found in ewes. However, owing to larger standard errors because of the smaller data sets, the gender difference in the derived $\mathrm{h}^{2}$ estimates for rams and ewes did not approach significance $(\mathrm{P}<0.10)$.

No clear genetic trends in log transformed FEC were discernable over the interval for which data were available (Figure 2), and it is obvious that none of the lines were subjected to directed selection to reduce FEC. Up to 2001, annual predicted breeding values for the line selected for clean fleece weight were generally higher than particularly the Wet and Dry line, with a few exceptions. The Control line was intermediate in most instances. The differences between lines were smaller since the year 2002, when only the Fleece weight selected line and the Control line were depicted. Overall means for breeding values of log transformed FEC were $0.124 \pm 0.007$ for the line selected for clean fleece weight, $0.054 \pm 0.006$ for the Control line, $-0.036 \pm 0.007$ for the Fine wool line and $-0.045 \pm 0.006$ for the Wet and Dry line. These comparisons are complicated by the fact that the Wet and Dry line and the Fine wool line were present for only part of the study period (1995 to 2002 for the Wet and Dry line and 1998 to 2005 for the Fine wool line). However, the overall means suggested that the line selected for clean fleece weight was the most susceptible to internal parasites, with the Wet and Dry and Fine wool lines being the most resistant $(\mathrm{P}<0.05)$. The Control line was intermediate and significantly different from all the other lines $(\mathrm{P}<0.05)$.

Further analyses involving the genetic correlations of FEC with two-tooth live weight and wool traits were based on a log transformation of FEC. A favourable (i.e. negative) genetic correlation of log transformed FEC with staple strength approached -0.50 (Table 4). The negative correlation with live weight did not differ from zero, although it exceeded -0.10 . The favourable genetic correlation (positive in this case because low values are desired for both traits) of log transformed FEC with CV of fibre diameter amounted to 0.30 . Clean fleece weight was unfavourably related to log transformed FEC, but the correlation was still low at $\sim 0.20$. For practical purposes, fibre diameter and total fold score were unrelated to FEC on a genetic level, the absolute value of both correlations being lower than 0.03 .

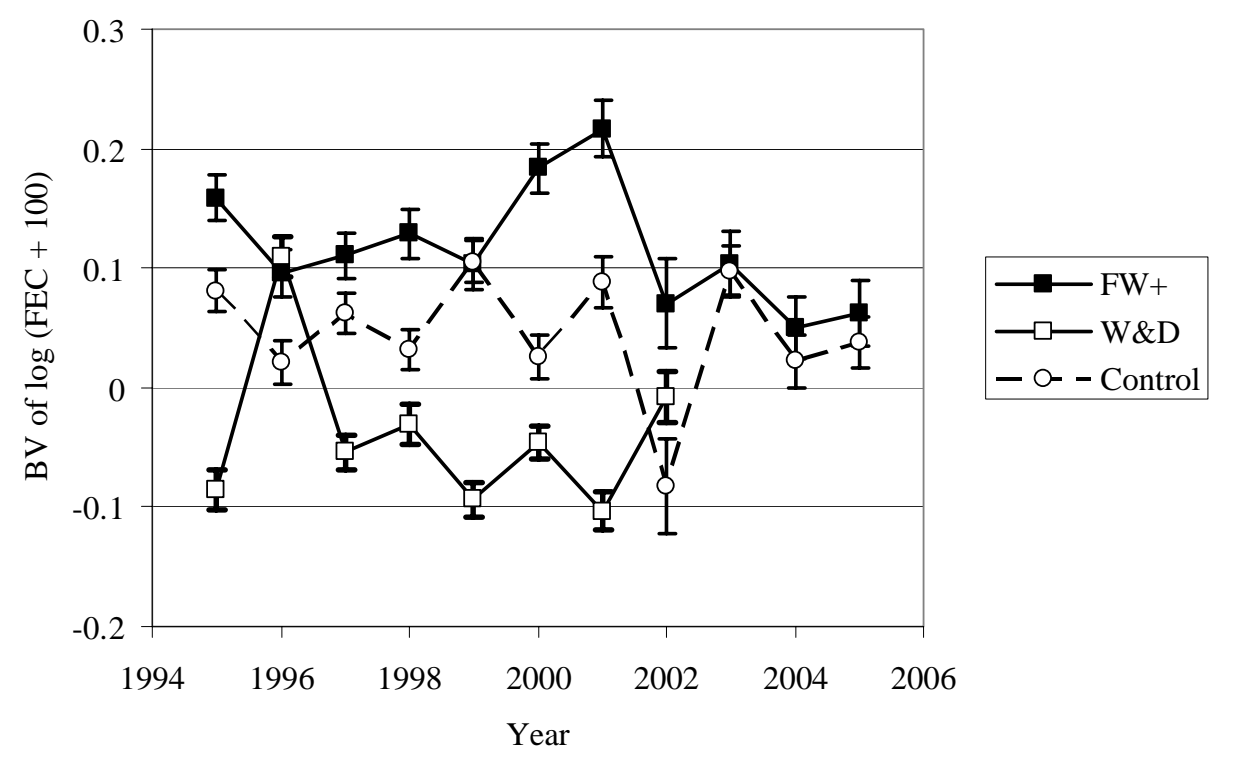

Figure 2 Averaged annual predicted breeding values for log transformed FEC according to selection line (FW+ - line selected for clean fleece weight; W\&D - Wet and Dry line; Control - unselected control line). Vertical bars on graph represent standard errors. (FEC - faecal worm egg count) 
Table 4 Genetic, environmental and phenotypic correlations ( \pm s.e.) of log transformed FEC with two-tooth live weight and wool traits

\begin{tabular}{lccc}
\hline Correlated trait & \multicolumn{3}{c}{ Type of correlation } \\
\cline { 2 - 4 } & Genetic & Environmental & Phenotypic \\
\hline Live weight $(\mathrm{kg})$ & $-0.119 \pm 0.098$ & $-0.074 \pm 0.034$ & $-0.078 \pm 0.018$ \\
Clean fleece weight $(\mathrm{kg})$ & $0.190 \pm 0.089$ & $-0.025 \pm 0.035$ & $0.039 \pm 0.018$ \\
Fibre diameter $(\mu \mathrm{m})$ & $-0.026 \pm 0.082$ & $-0.036 \pm 0.048$ & $-0.025 \pm 0.019$ \\
Staple strength $(\mathrm{N} / \mathrm{ktex})$ & $-0.493 \pm 0.126$ & $0.054 \pm 0.038$ & $-0.066 \pm 0.023$ \\
CV of fibre diameter $(\%)$ & $0.298 \pm 0.089$ & $-0.030 \pm 0.040$ & $0.081 \pm 0.020$ \\
Total fold score $(\mathrm{n})$ & $0.003 \pm 0.104$ & $0.008 \pm 0.032$ & $0.006 \pm 0.019$
\end{tabular}

FEC - faecal worm egg count

Phenotypic and environmental correlations of log transformed FEC with two-tooth live weight were in the same direction as the genetic correlation, but of a somewhat smaller magnitude (Table 4). Environmental correlations for the wool traits with log transformed FEC were not significant. The favourable phenotypic correlations of log transformed FEC with live weight, staple strength and CV of fibre diameter were significant $(\mathrm{P}<0.05)$, but below 0.10 .

\section{Discussion}

Marked variation is commonly reported for FEC data. Means for FEC in three contemporary groups ranged from 612 to 7010 (Eady, 1995). Snyman (2007) reported individual FEC values ranging from 0 to 87800 in the Klerefontein Afrino flock. Khusro et al. (2004) reported respective means of 779 and 736 eggs per gram of faeces for yearling and hogget Merino sheep in the Australian National evaluation. Individual FEC values ranged from 0 to $>50000$ in both age groups. The transformations applied to the present data are commonly used in the literature. In their documentation involving genetic parameters for sheep, Safari \& Fogarty (2003) list $26 \mathrm{~h}^{2}$ estimates for FEC, of which a cube root transformation has been applied in 12 cases, and a log transformation in 14 cases. Means in these studies ranged from 2.75 to 22.6 for cube root transformed FEC and from 6.88 to 7.49 for log transformed FEC. In New Zealand Perendale sheep, log transformed FEC averaged 5.98 at 22 weeks of age and 6.20 at 30 weeks of age (Morris et al., 2005). Results from the present investigation are consistent with these literature reports.

Results pertaining to the sex effect on FEC were variable in the study of Khusro et al. (2004). In yearling animals, rams had a lower mean for FEC than ewes, while the opposite was true in hoggets. The latter authors suggest that care should be taken in the interpretation of these results, as the experimental animals are always separated on gender. The same reasoning applies to the present investigation, where gender effects differed between years. In the study of Khusro et al. (2004) sex was completely confounded with contemporary group, and sex effects were removed by fitting contemporary group, much like the sex $\mathrm{x}$ year interaction constituted contemporary groups in this study. The lower FEC of multiples compared to singles is supported by a corresponding birth type difference in the study of Khusro et al. (2004). The latter study found no effects of dam age (fitted as a regression) on hogget FEC, as was also found in the present study.

Genetic parameters for FEC were included in the comprehensive review of genetic parameters for sheep (Safari et al., 2005). Earlier estimates included in this review will therefore not be cited, unless pertinent to this study. The present $\mathrm{h}^{2}$ estimates of 0.14 to 0.18 (depending on the transformation) are somewhat lower than the averaged estimate of 0.27 derived from 16 literature sources (Safari et al., 2005). At least some of these estimates were derived from studies where artificial challenge was used, and where more control can be exercised upon the challenge delivered to the animals. An $\mathrm{h}^{2}$ of 0.15 was estimated for cube root transformed FEC in naturally challenged Merino sheep under Mediterranean conditions, under climatic conditions fairly similar to those experienced in the present study (Greeff et al., 1999). Khusro 
et al. (2004) reported an $\mathrm{h}^{2}$ of 0.21 for cube root transformed yearling FEC, while hogget FEC exhibited substantially more genetic variation with an $\mathrm{h}^{2}$ of 0.38 . These records were obtained from commercial properties, and limited information is available on the method of challenge. Pollott et al. (2004) reported that the $h^{2}$ of FEC increased from 0.20 at weaning to 0.65 at 400 days of age, with an average of 0.28 . An industry data set of $\sim 39000$ records yielded an $\mathrm{h}^{2}$ estimate of 0.24 for FEC, while the sire $\mathrm{x}$ environment interaction accounted for 3\% of the phenotypic variation (Pollot \& Greeff, 2004). Estimates of $\mathrm{h}^{2}$ of $\log$ transformed FEC amounted to 0.22 at 22 weeks of age and to 0.16 at 30 weeks of age in New Zealand Perendale sheep subjected to natural challenge (Morris et al., 2005). The latter study reported divergence in FEC after selection from 1986 to 2002. The $\mathrm{h}^{2}$ of untransformed FEC in South African Afrino sheep subjected to artificial challenge with 4000 to 6000 infective Haemonchus contortus larvae was estimated at 0.19 (Snyman, 2007). The significant genetic variation (linked to high levels of phenotypic variation) and good correspondence with parameter estimates in the literature suggest that genetic progress in FEC in the Mediterranean parts of South Africa is more than likely. Realised genetic gains were reported under similar conditions (Karlsson et al., 1995; Woolaston \& Piper, 1996; Morris et al., 2005). Selection for a reduced FEC is assumed to lead to benefits in parasite resistance with associated economic advantages in the local sheep flock, as was reported for Australian sheep flocks (Greeff et al., 2006).

Cube root transformed FEC and log transformed FEC were affected by a dam permanent environmental variance ratio amounting to $\sim 5 \%$ of the phenotypic variation. Safari et al. (2005) did not report maternal variance ratios for FEC in their overview of genetic parameters for sheep. However, Khusro et al. (2004) reported a maternal genetic effect of 0.06 for yearling FEC in their study, while no effect of the dam was evident for hogget FEC. The estimate for yearling FEC was in good agreement with the results of the present study. No attempt was made by Khusro et al. (2004) to partition the maternal variance in its genetic and permanent environmental components.

The Pearson's correlation between predicted breeding values for cube root transformed FEC and breeding values for log transformed FEC approached unity in the present study. A similar conclusion was made by Eady (1995) who found correlations of between 0.97 and 1.00 between breeding values derived from analyses on FEC using the square root, cube root and log transformations. Depending on the nature and distribution of the FEC data, both transformations may be applicable to South African data sets.

Selection line means for log transformed breeding values for FEC suggest that the line selected for clean fleece weight was more susceptible to internal parasitism than the other lines, and particularly the Wet and Dry and Fine wool lines. These means support phenotypic means reported previously by Cloete et al. (2000). The literature is undecided with regard to the genetic association of clean fleece weight with FEC. Unfavourable correlated responses were reported in the New Zealand literature for non-Merino breeds (Williamson et al., 1994; Morris et al., 2000; 2005). These results are supported by a fairly high unfavourable genetic correlation of 0.56 reported recently by Morris et al. (2005). Results from the present study would support these results, although the genetic correlation between log transformed FEC and clean fleece weight reported in Table 4 was substantially lower at 0.19. The latter correlation is in fair agreement with corresponding values of 0.15 and 0.13 reported by respectively Eady et al. (1998) and Morris et al. (2000). Khusro et al. (2004) reported the genetic correlation of FEC with greasy fleece weight at 0.07 in both yearlings and hoggets. The corresponding genetic correlations between FEC and clean fleece weight were 0.11 in yearlings and -0.01 in hoggets. Another industry data set yielded an overall genetic correlation of 0.05 between FEC and greasy fleece weight (Pollot \& Greeff, 2004). In contrast, the overall genetic correlation between FEC and clean fleece weight derived from four literature sources by Safari et al. (2005) amounted to 0 . This low correlation is supported by no evidence of a correlated response in clean fleece weight to selection for a reduced FEC in the Rylington Merino flock (Greeff et al., 1999). In fact, no unfavourable correlated responses in any other production trait to selection for a reduced FEC were found by Karlsson et al. (1995). Even though some literature sources suggest an unfavourable genetic correlation between fleece weight and FEC in sheep, this relationship may not be sufficiently strong to preclude genetic progress in both traits in Merinos.

The genetic correlation of live weight with FEC was favourable (i.e. negative) but not significant. Corresponding genetic correlations (number of references) derived by Safari et al. (2005) from literature estimates were -0.03 for weaning weight (5), -0.24 for post-weaning weight (4) and -0.12 for mature weight (3). It has to be conceded that the derived estimates were associated with wide confidence intervals, 
including positive values in all instances. Estimates obtained from the Australian National Merino Evaluation were -0.14 for yearling weight and -0.02 for hogget weight (Khusro et al., 2004). Favourable genetic correlations of respectively -0.09 and -0.32 between FEC and live weight of Merinos were reported by Pollott \& Greeff (2004) and by Pollott et al. (2004). The genetic correlation obtained in the present study is consistent with these estimates pertaining to sign and magnitude. Conversely, the genetic correlation of FEC with live weight in New Zealand Perendales was positive and fairly high at 0.36 (Morris et al., 2005).

Fibre diameter appeared to be fairly independent of FEC on the genetic level. Safari et al. (2005) used three literature values to derive an averaged value of 0.01 , while Khusro et al. (2004) obtained estimates of -0.05 for both yearling and hogget FEC. The corresponding estimate derived by Pollott \& Greeff (2004) amounted to -0.04 . All these estimates accorded with the value of -0.03 reported in the present study. Previous estimates for the genetic correlation of FEC with staple strength were variable, and generally lower than the present estimate of -0.49 . Literature values included positive (i.e. unfavourable) estimates of 0.15 and 0.21 (Greeff \& Karlsson, 1998) and 0.13 (Greeff \& Karlsson, 1999). At -0.20, the genetic correlation reported by Pollott \& Greeff (2004) between FEC and staple strength were similar in sign but lower in magnitude compared to the present study. However, a random regression approach yielded smaller estimates. Pollott \& Greef (2004) attributed the discrepancy between the point estimate and results yielded by the random regression approach to a relatively low number of animals with staple strength records. Based on these differences between literature sources, further research on the genetic relationship of FEC with staple strength appears to be warranted.

The genetic correlation of FEC with CV of fibre diameter was positive (i.e. favourable) in the present study. Three comparable estimates reported by Greeff \& Karlsson $(1998 ; 1999)$ ranged from -0.05 to 0.10 . Two of these estimates were in the same direction as the correlation reported in Table 4, but smaller in magnitude. The genetic correlation of FEC with total fold score was negligible. No comparable results were found in the literature.

Phenotypic correlations derived from the literature for FEC with the other two-tooth traits were -0.08 for post-weaning live weight, 0.00 for clean fleece weight, and -0.02 for fibre diameter (Safari et al., 2005). Phenotypic correlations of FEC with traits assessed in the Australian National Merino database were -0.02 with yearling live weight, 0.02 with yearling clean fleece weight and 0.01 with yearling fibre diameter (Khusro et al., 2004). Corresponding correlations at a hogget age were $-0.06,0.02$ and -0.02 . These estimates were broadly consistent with those obtained in the present study.

\section{Conclusions}

Directed selection for the reduction of FEC seems feasible under natural challenge conditions in the Mediterranean parts of South Africa. According to Morris et al. (2004), a sound strategy for selection against intestinal nematode infestation should include resistance to worm infestation (as reflected by a low FEC) as well as resilience, i.e. an ability to maintain production in the presence of a parasite burden. The net effect of such a strategy would be a minimum contamination of the pasture being utilised, as well as minimal anthelminthic intervention. Age at first drench was considered as a measure of resilience in the latter study. This trait had an $\mathrm{h}^{2}$ of 0.14 , and was shown to respond to selection.

Selection for FEC is unlikely to result in marked unfavourable correlated responses in wool traits and live weight. The exception to this rule is clean fleece weight which may respond unfavourably when selection is based on FEC. However, with a genetic correlation of below 0.20 it seems as if genetic progress in both traits should be attainable, should it be desired. Research on genetic parameters for FEC and other traits of economic importance should continue to ensure that internal nematode control is dealt with in a sustainable manner in South African sheep flocks.

\section{Acknowledgements}

The inputs of the farm workers at Tygerhoek and the technical staff responsible for the faecal egg counts are gratefully acknowledged. 


\section{References}

Bath, G.F., 2006. Practical implementation of holistic internal parasite management in sheep. Small Rumin. Res. 62, 13-18.

Bisset, S.A., Van Wyk, J.A., Bath, G.F., Morris, C.A., Stenson, M.O. \& Malan, F.S., 2001. Phenotypic and genetic relationships among FAMACHA score, faecal egg count and performance data in Merino sheep exposed to Haemonchus contortus infection in South Africa. Proc. $5^{\text {th }}$ Int. Sheep Vet. Congress, Cape Town, South Africa. CD-communication.

Cloete, S.W.P. \& Scholtz, A.J., 1998. Lamb survival in relation to lambing and neonatal behaviour in medium wool Merino ewes divergently selected for multiple rearing ability. Aust. J. Exp. Agric. 38, 801-811.

Cloete, S.W.P., Dreyer, F.H. \& Du Toit, E., 2000. Faecal nematode egg counts in Merino sheep following natural challenge. S. Afr. J. Anim. Sci. 30 (Supplement 1), 24-25.

Cloete, S.W.P., Olivier, J.J., Snyman, M.A. \& Du Toit, E., 1998. Genetic parameters and trends in a selection experiment for increased clean fleece weight involving South African Merinos. Aust. J. Exp. Agric. 38, 427-432.

Eady, S.J., 1995. Implications of non-normal distribution of faecal egg count for measuring worm resistance in Merino sire evaluation schemes. Proc. Aust. Assoc. Anim. Breed. Gen. 11, 79-83.

Eady, S.J., Woolaston, R.R., Lewer, R.P., Raadsma, H.W., Swan, A.A. \& Ponzoni, R.W., 1998. Resistance to nematode parasites in sheep: correlation with production traits. Aust. J. Agric. Res. 49, 1201-1211.

Gilmour, A.R., Cullis, B.R., Welham, S.J. \& Thompson, R., 1999. ASREML reference manual. NSW Agriculture Biometric Bulletin No. 3. NSW Agriculture, Orange Agricultural Institute, Forest Rd, Orange 2800, NSW, Australia.

Greeff, J.C. \& Karlsson, L.J.E., 1998. The genetic relationship between faecal consistency, faecal worm egg counts and wool traits in Merino sheep. Proc. $8^{\text {th }}$ World Congress Gen. Appl. Livest. Prod. 24, 63-66. Armidale, Australia.

Greeff, J.C. \& Karlsson, L.J.E., 1999. Will selection for decreased faecal worm egg count result in an increase in scouring? Proc. Aust. Assoc. Anim. Breed. Gen. 13, 508-511.

Greeff, J.C., Karlsson, L.J.E. \& Harris, J.F., 1995. Heritability of faecal worm egg count at different times of the year in a Mediterranean environment. Proc. Aust. Assoc. Anim. Breed. Gen. 11, 117-121.

Greeff, J.C., Karlsson, L.J.E. \& Besier, R.B., 1999. Breeding sheep for resistance to internal parasites. In: Rising to the Challenge - Breeding for the $21^{\text {st }}$ Century Consumer. Beef industry and CRC for Premium Quality Wool Industry Simposia. Proc. Aust. Assoc. Anim. Breed. Gen. 13, 150-155.

Greeff, J.C., Karlsson, L. \& Underwood, N., 2006. Breeding Merino sheep for worm resistance increases profit in a Mediterranean environment. Proc. $8^{\text {th }}$ World Congress Gen. Appl. Livest. Prod., Bello Horizonte, Brazil. Communication 15-08.

Karlsson, L.J.E., Greeff, J.C. \& Harris, J.F., 1995. Genetic trends in selection line for low faecal worm egg count. Proc. Aust. Assoc. Anim. Breed. Gen. 11, 122-125.

Khusro, M., Van der Werf, J.H.J., Brown, D.J. \& Ball, A., 2004. Across flock (co)variance components for faecal worm egg count, live weight, and fleece traits for Australian Merinos. Livest. Prod. Sci. 91, 35-43.

Matebesi, P.A., Cloete, S.W.P. \& Van Wyk, J.B., 2007. Genetic parameters for subjectively assessed wool traits and objectively measured wool traits and live weight in the Tygerhoek Merino flock. Proc. Assoc. Advmnt Anim. Breed. Gen. 17, 332-335.

McEwan, J.C., Dodds, K.G., Watson, T.G., Greer, G.J., Hosking, B.C. \& Douch, P.G.C., 1995. Selection for host resistance to roundworms by the New Zealand sheep breeding industry: the Wormfec service. Proc. Aust. Assoc. Anim. Breed. Gen. 11, 70-73.

Morris, C.A., Amyess, N.C., Bisset, S.A. \& MacKay, A.D., 2004. Resilience to nematode parasitic challenge in industry and AgResearch selection flocks. Proc. N. Z. Soc. Anim. Prod. 64, 300-303.

Morris, C.A., Clarke, J.N., Watson, T.G., Wrigglesworth, A.L. \& Dobbie, J.L., 1996. Faecal egg count and food intake comparisons of Romney single-trait selection and control lines. N. Z. J. Agric. Res. 39, 371-378. 
Morris, C.A., Vlassoff, A., Bisset, S.A., Watson, T.G., West, C.J. \& Wheeler, M., 2000. Continued selection of Romney sheep for resistance or susceptibility to nematode infection: Estimates of direct and correlated responses. Anim. Sci. 70, 17-27.

Morris, C.A., Wheeler. M., Watson, T.G., Hosking, B.C. \& Leathwick, D.M., 2005. Direct and correlated responses to selection for high or low faecal nematode egg count in Perendale sheep. N. Z. J. Agric. Res. 48, 1-10.

Nieuwoudt, S.W., Theron, H.E. \& Krüger, L.P., 2002. Genetic parameters for resistance to Haemonchus contortus in Merino sheep in South Africa. J. S. Afr. Vet. Med. Assoc. 73, 4-7.

Pollot, G.E. \& Greeff, J.C., 2004. Genotype x environment interactions and genetic parameters for fecal worm egg counts and production traits of Merino sheep. J. Anim. Sci. 82, 2840-2851.

Pollot, G.E., Karlsson, L.J.E., Eady, S. \& Greeff, J.C., 2004. Genetic parameters for indicators of host resistance to parasites from weaning to hogget age in Merino sheep. J. Anim. Sci. 82, 2852-2864.

Olivier, J.J., Bezuidenhout, A.G., Greyling, A.C. \& Cloete, S.W.P., 1999. Evaluation of genetic fine and strong $x$ fine wool Merinos on irrigated pastures. Proc. Assoc. Advmnt Anim. Breed. Gen. 13, 62-65.

Safari, A. \& Fogarty, N.M., 2003. Genetic parameters for sheep production traits: Estimates from the literature. Tech. Bull. No 49, NSW Agriculture, Orange NSW, Australia.

Safari, E., Fogarty, N.M. \& Gilmour, A.R., 2005. A review of genetic parameter estimates for wool, growth, meat and reproduction traits in sheep. Livest. Prod. Sci. 92, 271-289.

Snyman, M.A., 2007. Prospects for the utilization of variation in parasite resistance among individual sheep within a flock. Grootfontein Agric 7 (1), 29-34.

Van Schalkwyk, L.W., Schröeder, P.C., Malan, F.S. \& Van Wyk, J.A., 1994. McMaster method of faecal worm egg counts. In: Worm workshop: Recommendations on worm control. pp 19-21.

Vatta, A.F., Krecek, R.C., Du Plessis, A., Havemann, A.R. \& Van der Merwe, J.S., 2000. Workshops propose national programme for veterinary helminthology in South Africa. J. S. Afr. Vet. Assoc. 71, 2-5.

Williamson, J.F., Blair, H.T., Garrick, D.J., Pomroy, W.E. \& Douch, P.G.C., 1994. The relationship between internal parasite burden, faecal egg count, and mucosal mast cells in fleeceweight-selected and control sheep. Proc. N. Z. Soc. Anim. Prod. 54, 9-13.

Woolaston, R.R. \& Piper, L.R., 1996. Selection of Merino sheep for resistance to Haemonchus contortus: genetic variation. Anim. Sci. 62, 451-460. 